\title{
Professor Raymond Dart
}

DIPLOMA CEREMONY PRETORIA SCHOOL OF PHYSIOTHERAPY, 10th FEBRUARY, 1961

\author{
Introductory Speech made by Dr. J. D. VERSTER \\ Assistant Superintendent, Pretoria General Hospital
}

Extract of Speech made by Dr.J. D. Verster, at the Diploma Ceremony of the Physiotherapy School, 10th February, 1961

To most of us in South Africa, the name of Professor Dart is closely associated with anthropology and in particular to research in that field. Professor Dart is known as the discoverer of the famous Taungs Skull in 1924.

Professor Dart has earned world renown not only in the field of Anthropology, but also in the fields of Medical Science and Education. For many years he was Professor of Anatomy at the Medical School of the Witwatersrand University.

From 1925-1943 he was also Dean of the Faculty of Medicine of the Medical School.

As a member of the Medical Council, Nursing Council, and the South African Institute for Medical Research. Professor Dart has rendered extensive service to the South African world of research and culture. What is perhaps less known, is the fact that Professor Dart has been associated with the institution of Academic Courses leading to Professional qualifications in Physiotherapy and Occupational Therapy.

Numerous degrees and distinctions have been conferred on Professor Dart, only one of which I wish to mention at the moment, that is the Gold Medal of the South African Association for the Advancement of Science.

Professor Dart has influenced many young South Africans to enter the field of Medical Research and his students, not only in South Africa, but elsewhere, do him credit.

To me the following extract from a copy of the South African Medical Journal gives a true picture of the kind of man we have with us today.

"It is perhaps Professor Dart's faculty for encouraging the best from his students and colleagues and for arousing their enthusiasm which has made its most memorable impression."

We are also put in mind of the words of Longfellow:

\section{Lives of great men all remind us}

We can make our lives sublime

and, departing, leave behind us

Footprints on the sand of time.

You, Sir, have made your mark, you have left your footprints deeply embedded on the sands covering various South African fields of human endeavour.

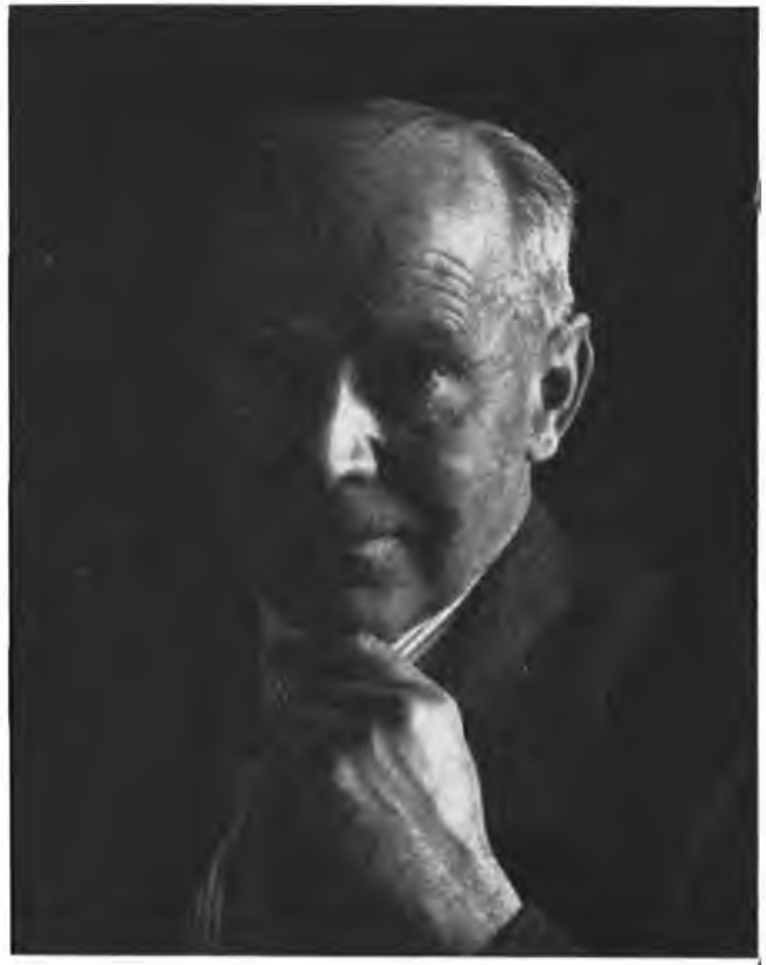

\section{PROFESSOR RAYMOND DART}

Emeritus Professor, University of the Witwatersrand

President of The South African Society of Physiotherapy

\section{Contents}

Page

Prof. Raymond A. Dart

2

History of Physiotherapy in South Africa $\quad \ldots \quad$.. 3

Treatment Notes-Rehabilitation of HemiplegiaMiss Jennings . $\cdots$. . . .

Treatment Notes-Does Your Wheelchair Fit?-Miss Humphrey
General

Question Box

Students' Column

Branch News ...

Vacancies

.

Medical Aid Societies 